\title{
Using Risk Factor Weighting to Target and Create Effective Public Health Policy for Campylobacteriosis Prevention in Ontario, Canada
}

\author{
Andrew Papadopoulos*, Emily Vellekoop, Mai Pham, Ian Young, Nicole Britten \\ Department of Population Medicine, University of Guelph, Guelph, Canada \\ *Corresponding author: apapadop@uoguelph.ca
}

Received January 18, 2013; Revised February 11, 2013; Accepted February 15, 2013

\begin{abstract}
Campylobacter is one of the major causes of foodborne illness globally, making prevention of Campylobacter infections a significant public health concern. Factors such as under-reporting and the low dose required to cause illness make surveillance and control of food-acquired campylobacteriosis challenging. A literature review was conducted to identify articles that included relevant information about the causes of foodborne illness, transmission of Campylobacter, specific risk factors associated with food-acquired Campylobacter infection and reported numbers of cases of Campylobacter. The majority of studies determine that specific demographic groups are at a higher risk for contracting foodborne illness, with age, gender, and location being the most significant factors. Food-acquired campylobacteriosis accounts for up to 74 to $85 \%$ of total cases, with poultry being the number one contributing vehicle. Location of food-acquired Campylobacter infection differs between countries. In Ontario, the majority of food-acquired campylobacteriosis cases are attributed to food prepared in the home. A risk factor diagram shows the source of Campylobacter organisms and the locations where people are exposed. It then shows causes of food-acquired Campylobacter infection, dividing them into human and non-human factors. Human factors are the major contributing causes of Campylobacter infection in people. Targeted policies should be developed which target these factors and address the specific groups that are at a higher risk for foodborne illness. Policy initiatives that focus on consumer level human factors will have the greatest impact on campylobacteriosis prevention. Further research needs to be conducted to determine the proportion of foodborne illness which can be attributed to specific risk factors and why consumers and food handlers do not follow proper procedures for minimizing exposure to Campylobacter organisms. Targeted policies can provide a more cost-effective way to help prevent further cases of Campylobacter infection as well as improve disease surveillance.
\end{abstract}

Keywords: Campylobacter infection, foodborne illness, targeted policy, campylobacteriosis, prevention, risk factor weighting, public health policy

\section{Introduction}

Campylobacter is one of the major causes of foodborne illness world-wide and is considered to be the causative agent of 5 to $15 \%$ of the global incidence of diarrheal diseases $[1,2,3,4]$. Usual symptoms of campylobacteriosis include diarrhea, malaise, fever, and abdominal pain; however, serious sequelae can include reactive arthritis, inflammatory bowel disease, and Guillain-Barré syndrome $[1,5,6,7]$. The economic costs of campylobacteriosis in HALYs (health adjusted life-years) are determined to be approximately $146 \mathrm{HALY} /$ year in Ontario [8]. There is a conservative estimated total prevalence of 88566 cases of campylobacteriosis in Ontario per year and Campylobacter is the leading cause of foodborne illness in Canada making prevention of Campylobacter infections a significant public health concern $[6,8,9]$.

Campylobacter infection has an incubation period between one and eleven days, averaging three days before the onset of symptoms [5]. Infections are usually selflimiting and persist for about one week [5]. As a result, under-reporting of Campylobacter infection occurs frequently with an estimated minimum rate of 23 cases per one reported case [10].A very low dose of Campylobacter organisms are required to cause infection in humans making surveillance systems designed to monitor the number of contracted Campylobacter infections difficult to implement. [5]. A better understanding of the causes and risk factors associated with food-acquired Campylobacter infection will allow for the development and implementation of targeted public health initiatives. Targeted policies can provide a more cost-effective way to help prevent further cases of Campylobacter infection as well as improve disease surveillance.

A risk factor diagram is a tool that can be used to weight the importance of various factors involved in a specific event. The sequence of factors and the number of intervening variables can help show the temporal sequence of cause and effect relationships within a transmissible disease [11]. A risk factor diagram is also a valuable tool in assessing areas where further research and data collection need to occur. In this case, a sequential risk factor diagram can illustrate the importance of factors 
contributing to human campylobacteriosis, and identify specific areas for further investigation.

This article will identify the causes and risk factors of food-acquired Campylobacter infection, and present them as a risk factor diagram to graphically portray the relationships and importance of each variable. This visual representation will allow for the isolation of areas where targeted public policy initiatives can help prevent the spread of food-acquired campylobacteriosis.

\section{Materials and Methods}

A literature review was completed in July 2011, with a follow-up search conducted in August 2011 to ensure completeness. Databases searched include PubMed (MEDLINE), Agricola, bioOne, Scholar's Portal, CIHI and CBCA. See Table 1 for key words used in search query.

Table 1. Key words used in search query

\begin{tabular}{|l|l|l|l|}
\hline foodborne & food related & $\begin{array}{l}\text { food } \\
\text { associated }\end{array}$ & $\begin{array}{l}\text { contaminated } \\
\text { food }\end{array}$ \\
\hline Disease & illness & sickness & Campylobacter \\
\hline Bacteria & Campylobacter & $\begin{array}{l}\text { Campylobacter } \\
\text { jejuni }\end{array}$ & $\begin{array}{l}\text { Cami } \\
\text { coli }\end{array}$ \\
\hline Factor & risk factor & causes & \\
\hline Canada & Ontario & & \\
\hline Comparison & investigation & & \\
\hline
\end{tabular}

Terms within rows were combined with "OR" and terms from all the rows were combined with "AND". Various combinations of search terms were used to narrow and broaden search results. Further articles were located by manually reviewing the reference lists of relevant articles. Articles citing other relevant studies are included in our bibliography. A few relevant reference books were also included.

All papers identified by the search were initially screened for relevance using the title and/or abstract. Literature was restricted to only those written in the English-language. Abstracts were then reviewed by a member of the research team and were included in the study if the abstract contained information about the cause(s) of foodborne-related Campylobacter infection, specific risk factors associated with foodborne-related Campylobacter infection, and the reported numbers of cases of Campylobacter infection in a particular jurisdiction. Any epidemiological studies relating to Campylobacter infection or general foodborne illness in Canada were also included.

The literature search was confined to countries with similar food regulatory and socioeconomic status to Canada such as the United States, the United Kingdom and Europe, Australia, and New Zealand. Other exclusion criteria included any articles published before 1991 (20 years), articles discussing non-food related Campylobacter infection, and articles that described the physiological characteristics of the Campylobacter micro-organism.

\section{Results}

There are several species of Campylobacter which cause diarrheal disease in humans but the most prevalent in foodborne illness are Campylobacter jejuni and Campylobacter coli [4]. In Canada, C. jejuni is about six times more prevalent than $C$. coli and it is responsible for $85 \%$ of human campylobacteriosis cases [2,12]. This finding is similar to a Danish study showing that $C$. jejuni is responsible for $89 \%$ of human infections and $C$. coli for $10 \%$ [5]. Other Campylobacter species contribute to approximately $1 \%$ of human cases [5]. The studies cited in this article refer to infections caused by all Campylobacter species.

Specific demographic groups are at higher risk for contracting a foodborne illness. A study based in England and Wales indicates that age, gender, ethnicity, and socioeconomic class are all significant demographic determinants for contracting a foodborne illness; however, most studies determine the significant demographic factors to be age, gender, and location. [1,8,13,14,15]. Most studies indicate a higher percentage of foodborne illness in males than females; however, a report by the Ontario Burden of Infectious Disease Advisory Group states that there is an equal distribution of Campylobacter infections between males and females [6,8,16,17]. A Canadian study indicates that individuals in a rural setting living in close proximity to high density farming are more likely to contract foodborne illness, specifically Campylobacter [18]. As with most foodborne illnesses, age distribution for Campylobacter follows a bimodal distribution [17,19]. The Public Health Agency of Canada reports that infants and young children are the most at risk, followed by young adults [2]. Australian, US, and Finish data confirm these age groups, specifically children from ages zero to four, and adults ages 20 through 29 $[6,13,17,19,20]$.

The Campylobacter organism enters the food chain through its presence in several reservoirs including manure pits filled with animal fecal matter on farms, on contaminated equipment and in water tanks within slaughter plants, and in drinking water supplies [9,21]. Studies are available which show variables influencing infection of live birds with Campylobacter species and Hazard Analysis Critical Control Points (HACCP) studies of the slaughter process show specific areas where contamination occurs $[5,9,12,21,22,23]$. However, complete elimination of Campylobacter from food items cannot be accomplished and therefore the presence of Campylobacter in the human food supply will always be a serious public health concern.

Vehicles which contribute to Campylobacter infection include contact or consumption of contaminated meat (usually poultry and in particular poultry purchased raw), consumption of raw milk, consumption of contaminated drinking water, transmission from other animal species including young dogs and cats, and travel to locations where Campylobacter infection is highly prevalent such as farms and other rural locations both inside and outside of Canada $[1,10,24,25,26]$. The most significant source of human infection with Campylobacter spp is contaminated food items [27]. Food-acquired campylobacteriosis makes up to 74 to $85 \%$ of total disease cases [10,12,28,29]. Other factors collectively represent approximately 20 to $30 \%$ of campylobacteriosis cases [5,22,25,26,30]. Poultry, especially when purchased and handled raw or served undercooked is the main contributing food item and is responsible for about $35-40 \%$ of food-acquired Campylobacter infections, making it the number one contributing vehicle [5,22,25,26,29,31,32]. In Ontario, meat items (including poultry) and foods of animal origin 
are responsible for approximately $65 \%$ of all foodacquired illness [10,33].

Data showing the location where the highest risk of food-acquired Campylobacter infection occurs differ depending on the country where the data was collected. Some international studies show commercial food establishments have a higher risk. A study from the United States determined that poultry served in restaurants had the highest attributable fraction of cases and an Australian study determined that $55 \%$ of cases result from food served in a commercial establishment [24,29]. However, in Ontario, the majority of food-acquired illness occurs in private homes, with approximately $50 \%$ of foodacquired illness attributed to food prepared in the home $[5,10]$. Dutch and UK studies also show that the home is a high risk setting for acquiring foodborne illness [33,34].

A US study breaks the causes of food-acquired illness into two categories: human and non-human factors [35]. Non-human factors or environmental factors are the result of the facilities used and are generally more of a concern in commercial food establishments. However, even in commercial settings, human factors contribute to the majority $(63 \%)$ of food-safety violations [35]. In a private home setting, the only alterable explanatory variables of foodborne campylobacteriosis are human factors. The causes of campylobacteriosis are the same as most foodborne infectious agents, time-temperature abuse (maintaining food at a temperature that allows bacterial growth for a sufficient length of time), crosscontamination (transferring pathogenic organisms from surfaces, fomites, or other food) and poor hygiene practices [36]. Improper consumer hygiene practices can account for 40 to $60 \%$ of foodborne illness acquired in a home setting [34]. In a Dutch study, 4 to $43 \%$ of consumers reported improperly cleaning cutting boards, 7 to $74 \%$ reported not washing hands properly, and 3 to $48 \%$ reported improperly cleaning cutlery [34]. However, a follow-up observational study found much higher proportions of improper cleaning with values of $91 \%$, $100 \%$, and $61 \%$ respectively [34]. There is no direct quantitative data showing which of these general causes contributes the most to Campylobacter infection; however, cross-contamination is usually cited as the largest cause $[5,25,34]$. An estimate can be made based on a US study focusing on food safety violations in restaurants in the Las Vegas area, which indicated that $35 \%$ of violations are due to cross-contamination compared to $18 \%$ for timetemperature abuse, and $10 \%$ due to personal hygiene [35]. Please refer to Figure 1 for a graphical representation of the results.

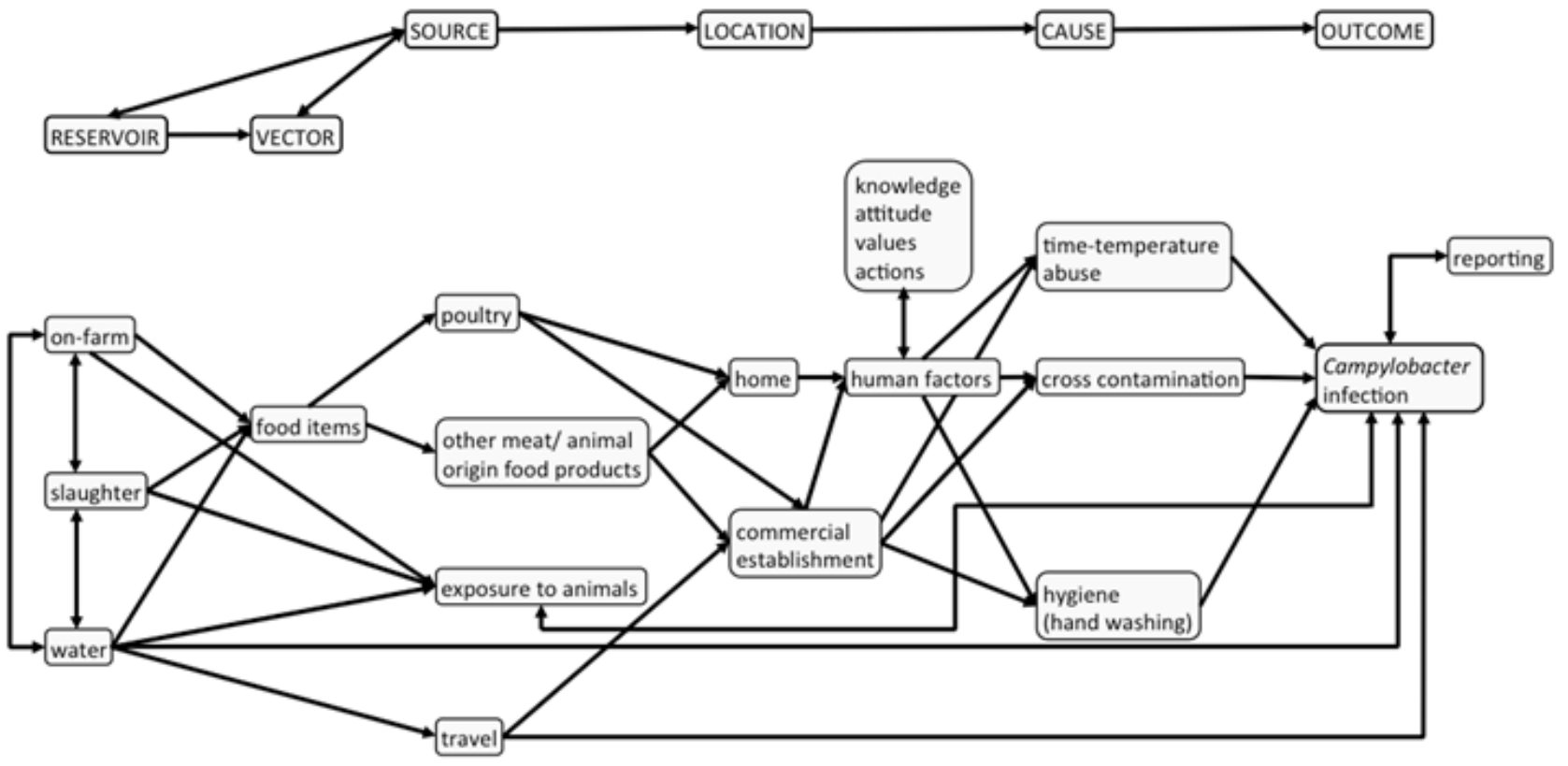

Figure 1. Campylobacter Risk Factor Diagram

This risk factor diagram shows the source of Campylobacter organisms and the locations where people are exposed. It then shows causes of food-acquired Campylobacter infection, dividing them into human and non-human factors. Human factors are the major contributing causes of Campylobacter infection in people.

\section{Discussion}

Campylobacter infections are a serious and expensive public health concern. The causes of Campylobacter infection are complex and often interrelated. Most foodborne Campylobacter infections are associated with poultry, in particular chicken. Although research has been conducted and policies and protocols are in place to reduce foodborne Campylobacter at the slaughter and farm levels, very little quantitative data on the infection and transmission of Campylobacter to humans from food sources is available. This data would be beneficial to any public health agency attempting to produce an effective policy aimed at reducing the number of human Campylobacter infections occurring in Ontario. An efficient public policy aimed at reducing the spread of foodborne Campylobacter could eliminate up to $80 \%$ of human Campylobacter infections [10,12,28,29].

As illustrated in the risk factor diagram for Campylobacter infections in Ontario, time-temperature abuse, cross-contamination, and personal hygiene (such as hand washing), defined as human factors, contribute significantly to risk of infection. Environmental factors (facility, level of contamination of raw food sources) do 
not contribute as much as human factors to human cases of campylobacteriosis. This illustrates that policy initiatives with the greatest impact will focus on consumer level human factors.

Organisms that cause foodborne illness, such as Campylobacter are ubiquitous in the environment and can be introduced into the food supply at all stages of the farm-to-fork continuum [37]. All stakeholders in the food chain, including the food industry, governments and consumers, have a role to play in ensuring the safety of the food we eat. Consumers are the final line of defense against foodborne illness; what they do, or fail to do, can have major implications for the food safety at the point of consumption regardless of how well the other players in the food chain perform their roles [37,38].

While outbreaks of foodborne illness are often associated with food consumed at restaurants and public eating establishments (e.g., cafeterias, delicatessens and hotels) $[39,40]$, sporadic cases of foodborne illness have been shown to be more frequently associated with food consumed at home [10]. In a study analyzing sporadic cases of enteric illness reported in Ontario from 1997 to 2001, approximately $50 \%$ of cases were linked to a home setting [10]. Consumers tend to expect the foods they purchase to be safe and they believe that there is a low risk of becoming ill after preparing and consuming food in their home $[39,41,42]$. A survey of food safety behaviours among Canadians in Waterloo, Ontario, during 2005-2006 found that the prevalence of some high-risk food safety practices was very high (e.g. consuming undercooked eggs), and the authors suggested a need for additional food safety education for consumers [43].

Educational interventions and programs targeted toward consumers are necessary to increase their knowledge and awareness about food safety, to change their food handling and preparation behaviours, and ultimately, to decrease the incidence of foodborne illness in Canada [39].

People who prepare food for themselves and others do not do so with the intent to harm or cause illness; however, food continues to be a vehicle for many bacterial, viral, and fungal infections. There is a gap in understanding between food preparation actions and resulting foodborne illness [39]. Successful programs and policies must address the knowledge gap surrounding causes of foodborne illness and actions consumers can take to keep themselves and others safe.

In Canada, food safety is a shared responsibility between the federal, provincial, territorial, and municipal levels of government [44]. The federal government has the principal responsibility for setting food safety standards and policies, ensuring industry compliance with food safety regulations, initiating food recalls, and developing national strategies for managing food safety risks $[37,38,44]$. Each provincial and territorial government has a public health mandate that includes food safety surveillance, investigations, and compliance inspections [44].Within each province, it is the regional health authorities or local public health units that deliver these public health programs and services to the community within their geographic borders. This level of public health agency has been delivering food handler training to food establishments, but have largely neglected consumers. Targeted consumer education can have a profound effect on the prevalence of foodborne illness. However, it is critical to ensure the education programs are targeted with the consumer in mind and that the programs are tailored to the consumers segment's needs and preferences.

Policies must be developed which address the specific demographic groups associated with a higher risk for contracting a foodborne infection. Foodborne illness is highest in both females and males of 20 to 29 years, which an Australian study attributes to more travel in this age group [19]. The "second weaning effect" describes the high incidence of foodborne illness in males between the ages of 20 to 29 . Generally, this is the age when males first start to prepare food for consumption; a possible lack of experience and knowledge relating to food handling allows for a higher risk of contamination and consumption of contaminated food items. Young children and infants under 4 years of age also have an increased risk of contracting a foodborne illness. This may be due to an increased symptom reporting on the part of care-givers however, there is also evidence of improper handling of bottles $[14,19]$. Policies must be accurately targeted at these specific demographic groups in order to make the greatest impact. It would be redundant and a poor utilization of resources to address the general population as some demographic groups already display adequate food handling behaviour.

Although cross-contamination can occur in restaurants and eating establishments, a significant amount of foodborne illness is acquired in a home setting. Further research needs to be conducted to determine the proportion of foodborne illness which can be attributed to specific risk factors and why consumers and food handlers do not follow proper procedures, including handwashing for minimizing exposure to Campylobacter organism. As well, research into the attitudes and beliefs of the public regarding foodborne illness must be conducted. Any data that will provide accurate weighting of infection rates is required. Further research is also needed to address the discrepancies between consumer reports and observational studies.

The limitations of this paper include the lack of information that is available to make a full assessment of the causes and risk factors of food-related Campylobacter infection. Furthermore, the information that is available is subject to detection bias due to the underreporting of foodborne illness, and information bias such as recall. Due to the lack of information, it is difficult to determine the generalizability of this work.

\section{Conclusion}

Campylobacter infections remain a major public health concern while a greater focus is being placed on the efficient use of scarce resources. A more focused and targeted approach to resolving public health issues within communities is required to ensure public health agencies have the greatest impact possible. Risk factor diagrams are an effective way to illustrate factors that contribute to campylobacteriosis and identify specific areas where further investigation is necessary. A risk factor diagram for Campylobacter infection shows that approximately $80 \%$ of these infections are caused by human factors, many occurring within the home. Targeting public policy and programs that would educate primary food handlers could have a significant impact on foodborne related illnesses within communities. Currently, few initiatives 
exist that educate consumers regarding safe food handling, yet they are the last line of defense against food borne illness. Targeted programming has proven to be a more effective means of delivering a successful message when resources are limited.

\section{Competing Interests}

Authors have no competing interests.

\section{References}

[1] Public Health Agency of Canada. Campylobacteriosis, Notifiable Diseases On-Line, Public Health Agency of Canada, 2003. [Edocument] Available:

http://dsol-smed.phac-aspc.gc.ca/dsol-smed/ndis/diseases/campeng.php.

[2] Public Health Agency of Canada. "Canadian Integrated Surveillance Report: Salmonella, Campylobacter, verotoxigenic E. coli and Shigella, from 2000-2004, Canadian Communicable Disease Report, 2009. [E-document] Available: http://www.phacaspc.gc.ca/publicat/ccdrrmtc/09vol35/35s3/campy lobacter-campylobacter-eng.php.

[3] Ternhag, A., Törner, A., Svensson, A., Giesecke, J. and Ekdahl, K, "Mortality following Campylobacter infection: a registry-based linkage study,” BMC Infectious Diseases, 5 (70), September 2005. [Online]. Available:

http://www.biomedcentral.com/1471-2334/5/70. [Accessed July 14, 2010].

[4] Patrick, M., Schlundt, J. and Braam, H. P, Control of Communicable Diseases Manual: Campylobacter Enteritis, Washington: American Public Health Association, Washington, 2008, 94-98.

[5] Rosenquist, H., Nielsen, N. L., Sommer, H. M., Nørrung, B. and Christensen, B. B, "Quantitative risk assessment of human campylobacteriosis associated with thermophilic Campylobacter species in chickens," International Journal of Food Microbiology, 83 (1), 87-103. May.2003.

[6] Arsenault, J., Ravel, A., Michel, P., Berke, O. and Gosselin, P, "Do patients with recurrent episodes of campylobacteriosis differ from those with a single disease event?," BMC Public Health, 11 (32), January 2011. [Online]. Available:

http://www.biomedcentral.com/1471-2458/11/32. [Accessed July 14, 2010].

[7] Altekruse, S. F., Stern, N. J., Fields, P. I. and Swerdlow, D. L, "Campylobacter jejuni--an emerging foodborne pathogen," Emerging Infectious Diseases, 5 (1), 28-35. Feb.1999.

[8] Kwong J.C., Crowcroft, N.S., Campitelli, M.A., Ratnasinham, S., Daneman, N. and Deeks, S.L, Ontario Burden of Infectious Disease Study (ONBOIDS): An OAHPP/ICES Report. Health Care. Ontario Agency for Health Protection and Promotion and the Institute for Clinical Evaluative Sciences, Toronto, 2010, 1198.

[9] Farzan, A., Friendship, R. M., Cook, A. and Pollari, F, "Occurrence of Salmonella, Campylobacter, Yersinia enterocolitica, Escherichia coli O157 and Listeria monocytogenes in swine," Zoonoses and Public Health, 57 (6), 388-96. Sept.2010.

[10] Lee, M. B. and Middleton, D, "Enteric illness in Ontario, Canada, from 1997 to 2001," Journal of Food Protection, 66 (6), 953-61. Jun.2003.

[11] Doohoo, I., Martin, W. and Stryhn, H, Introduction and Causal Concepts: Veterinary Epidemiologic Research, AVC Inc., Charlottetown, 2003, 10-24.

[12] Hannon, S. J., Inglis, G. D., Allan, B., Waldner, C., Russell, M. L., Potter, A., Babiuk, L. A. and Townsend, H. G. G, "Prevalence and Risk Factor Investigation of Campylobacter Species in Retail Ground Beef from Alberta, Canada," Food Protection Trends, 29 (11), 780-86. Nov.2009.

[13] Gillespie, I. A., O’Brien, S. J., Penman, C., Tompkins, D., Cowden, J. and Humphrey, T.J, "Demographic determinants for Campylobacter infection in England and Wales: implications for future epidemiological studies," Epidemiology and Infection, 136 (12), 1717-25. Dec.2008.

[14] Centers for Disease Control and Prevention (CDC) Department of Health and Human Services, Foodborne Illness: Frequently Asked
Questions. CDC, 2005, [E-document], Available: http://www.cdc.gov/ncidod/dbmd/diseaseinfo/foodborneinfections _g.htm

[15] Friedman, C. R., Neimann, J., Wegener, H. C., Tauxe, R. V., Oberhleman, R. A. and Taylor, D. N, Campylobacter, American Society for Microbiology, Washington, 2000, $121-153$.

[16] Potter, R. C., Kaneene, J. B. and Gardiner, J, "Comparison of Campylobacter jejuni Enteritis Incidence Rates in High- and LowPoultry-Density Countries: Michigan 1992 - 1999," Vector Borne and Zoonotic Diseases, 2 (3), 137-44. 2002.

[17] Tenkate, T. D. and Stafford, R. J, "Risk factors for Campylobacter infection in infants and young children: a matched case-control study," Epidemiology and Infection, 127 (3), 399-404. Dec.2001.

[18] Green, C. G., Krause, D. O. and Wylie, J. L, "Spatial analysis of Campylobacter infection in the Canadian province of Manitoba," International Journal of Health Geographics, 5, 2.,January 2006. [Online]. Available:

http://www.ij-healthgeographics.com/content/5/1/2. [Accesed July $14,2010]$.

[19] Stafford, R., Tenkate, T., Mccall, B., Zone, S., Health, P., Box, P. O. and Mt, U, "A Five Year Review of Campylobacter Infection in Queensland," Clinical and Developmental Immunology, 20 (22), 478-82. Oct.1996.

[20] Nakari, U.-M., Huovinen, E., Kuusi, M. and Siitonen, A, "Population-based surveillance study of Campylobacter infections in Finland," Epidemiology and Infection, 138 (12), 1712-8. Dec. 2010.

[21] Letellier, A. N. N., Cox, B., Leslie, M., Sanei, B., Young, I. A. N., Rajic, A. and Ewen, S. A. M. C, "Knowledge and Attitudes toward Food Safety and Use of Good Production Practices among Canadian Broiler Chicken Producers," Journal of Food Protection, 73 (7), 1278-87. Jul.2010.

[22] Guerin, M. T., Sir, C., Sargeant, J. M., Waddell, L., O’Connor, A. M., Wills, R. W., Bailey, R. H. and Byrd, J.A, "The change in prevalence of Campylobacter on chicken carcasses during processing: a systematic review," Poultry Science, 89 (5), 1070-84 Feb.2010

[23] Callicott, K. A., Harğardóttir, H., Georgsson, F., Reiersen, J., Friğriksdóttir, V., Gunnarsson, E., Michel, P., Bisaillon, J. R., Kristinsson, K. G., Briem, H., Hiett, K. L., Needleman, D. S. and Stern, N. J, "Broiler Campylobacter Contamination and Human Campylobacteriosis in Iceland," Applied and Environmental Microbiology, 74 (21), 6483-94. Nov.2008.

[24] Friedman, C. R., Hoekstra, R. M., Samuel, M., Marcus, R., Bender, J., Shiferaw, B., Reddy, S., Ahuja, S. D., Helfrick, D. L. Hardnett, F., Carter, M., Anderson, B. and Tauxe, R. V, "Risk factors for sporadic Campylobacter infection in the United States: A casecontrol study in FoodNet sites" Clinical Infectious Diseases, 38 (Suppl 3), S285-96. 2004.

[25] Kapperud, G., Espeland, G., Walh, E., Walde, A., Herikstad, H., Gustavsen, S., Tveit, I., Natas, O., Bevanger, L. and Digranes, A, "Factors Associated with Increased and Decreased Risk of Campylobacter Infection: A Prospective Case-Control Study in Norway," American Journal of Epidemiology, 158 (3), 234-42. Aug.2003.

[26] Ravel, A., Nesbitt, A., Marshall, B., Sittler, N. and Pollari, F, "Description and burden of travel-related cases caused by enteropathogens reported in a Canadian community," Journal of Travel Medicine, 18 (1), 8-19. Feb.2010.

[27] Ravel, A., Davidson, V. J., Ruzante, J. M. and Fazil, A, "Foodborne proportion of gastrointestinal illness: estimates from a Canadian expert elicitation survey," Foodborne Pathogens and Disease, 7 (12), 1463-72. Dec.2010.

[28] Clark, C. G., Price, L., Ahmed, R., Woodward, D. L., Melito, P. L., Rodgers, F. G., Jamieson, F., Ciebin, B., Li, A. and Ellis, A, "Characterization of Waterborne Outbreak - associated Walkerton , Ontario," Emerging Infectious Diseases, 9(10), 123241. Oct. 2003.

[29] Unicomb, L. E., Fullerton, K. E., Kirk, M. D. and Stafford, R. J, "Outbreaks of campylobacteriosis in Australia, 2001 to 2006," Foodborne Pathogens and Disease, 6 (10), 1241-1250. Dec.2009.

[30] Bryan, F. L. and Doyle, M. P, "Health risks and consequences of Salmonella and Campylobacter jejuni in raw poultry," Journal of Food Protection, 58 (3), 326-344. Mar.1995.

[31] Gellynck, X., Messens, W., Halet, D., Grijspeerdt, K., Hartnett, E. and Viaene, J, "Economics of reducing Campylobacter at different levels within the Belgian poultry meat chain," Journal of Food Protection, 71 (3), 479-85. Mar.2008. 
[32] Leifert, C., Ball, K., Volakakis, N. and Cooper, J. M, "Control of enteric pathogens in ready-to-eat vegetable crops in organic and "low input" production systems: a HACCP-based approach," Journal of Applied Microbiology, 105 (4), 931-50. Oct.2008.

[33] Worsfold, D. and Griffith, C, "Food safety behaviour in the home," British Food Journal, 99 (3), 97-104. 1997.

[34] de Jong, A. E. I., Verhoeff-Bakkenes, L., Nauta, M. J. and de Jonge, R, "Cross-contamination in the kitchen: effect of hygiene measures," Journal of Applied Microbiology, 105 (2), 615-24. Feb.2008.

[35] Choung, J, An Analysis of restaurant food safety violations: human factors, non-human factors, and food-borne illness. University of Nevada Las Vegas, 2010 [E-document] Available: http://digitalcommons.library.unlv.edu/thesesdissertations/458/.

[36] Miller Jones, J, Food Safety, American Association of Cereal Chemists, Inc.,St. Paul,1998, 1-453.

[37] Munro, D., Le Vallée, J.C. and Stuckley, J, Improving food safety in Canada: Toward a more risk-responsive system, The Conference Board of Canada, 2012. [E-report] Available: http://www.conferenceboard.ca/e-library/abstract.aspx?did=4671.

[38] Haines, R.J, Farm to fork: A strategy for meat safety in Ontario, Ontario Ministry of the Attorney General, Toronto, 2004. 1-559.
[39] Redmond, E.C. and Griffith, C.J, "Consumer food handling in the home: A review of food safety studies," Journal of Food Protection, 66 (1). 130-161. Jan.2003.

[40] Jones, T.F. and Angulo, F.J, "Eating in restaurants: A risk factor for foodborne disease?" Clinical Infectious Diseases, 43 (10), 1324-1328. Oct.2006.

[41] Ford, L.T., Penner, K.P. and Grunewald, O, "Consumer perceptions of HACCP and the price of meat,".Dairy, Food and Environmental Sanitation, 18. 735-741. 1998.

[42] Fein, S.B., Lando, A.M., Levy, A.S., Teisl, M.F. and Noblet, C, 2011. "Trends in U.S. consumers' safe handling and consumption of food and their risk perceptions, 1988 through 2010," Journal of Food Protection, 74 (9). 1513-1523. Sept.2011.

[43] Nesbitt, A., Majowicz, S., Finley, R., Marshall, B., Pollari, F., Sargeant, J., Ribble, C., Wilson, J. and Sutler, N, "High-risk food consumption and food safety practices in a canadian community," Journal of Food Protection, 72 (12). 2575-2586. Dec.2009.

[44] Health Canada and Canadian Food Inspection Agency, "The food safety regulatory system in Canada," in FAO/WHO Regional Conference on Food Safety for the Americas and the Caribbean. Health Canada and Canadian Food Inspection Agency, 1-7. 